\title{
Effect of the combination of Leptadenia hastata (pers) decne and Momordica balsamina linn leaf extracts on lipid profile of streptozotocin-induced diabetic rats
}

Nafisatu Kabir ${ }^{1 *}$ D, Umar Ismail Alhaji², Dorcas Bolanle James², Hajia Mairo Inuwa ${ }^{2}$ and Muhammad Kano Atiku ${ }^{3}$

\begin{abstract}
Background: Changes in blood lipid level (dyslipidemia) play a central role in the onset and pathogenesis of macrovascular complications of diabetes mellitus. Traditional herbal healers commonly use anti-diabetic polyherbal formulations to provide a multi-therapeutic approach for the treatment of diabetes mellitus and its associated complications. The effect of the aqueous leaf extracts of Leptadenia hastata (pers) Decne, Momordica balsamina Linn and their combination on lipid profile of streptozotocin (STZ)-induced diabetic rats was therefore evaluated in the present study.

Results: We evaluated the serum lipid profile and blood glucose level of STZ-induced diabetic rats $(60 \mathrm{mg} / \mathrm{kg}$ body weight) treated with the aqueous leaf extracts of L. hastata $(400 \mathrm{mg} / \mathrm{kg})$ and M. balsamina $(200 \mathrm{mg} / \mathrm{kg})$ alone and in combination $(400+200 \mathrm{mg} / \mathrm{kg})$ after a period of 4 weeks. A significantly decreased $(p<0.05)$ level of total cholesterol (TC), triglyceride (TG), very low-density lipoprotein (VLDL) and low-density lipoprotein (LDL) cholesterol levels and increased $(p<0.05)$ level of high-density lipoprotein $(H D L)$ cholesterol was observed in all the treated groups when compared to the untreated diabetic rats. Furthermore, the combination treatment was potentially a more effective blood lipid-lowering $(p<0.05)$ agent when compared to the single treatments.

Conclusion: Results from this study demonstrated the blood lipid-lowering potential of the aqueous leaf extracts of L. hastata, M. balsamina, and their combination. However, the polyherbal combination could be more potent in controlling diabetes mellitus, associated dyslipidemia, and its complications.
\end{abstract}

Keywords: Leptadenia hastata, Momordica balsamina, Streptozotocin, Blood glucose, Lipid profile, aqueous extract

\section{Background}

Diabetes mellitus (DM) affects essential pathways of carbohydrate, protein, and lipid metabolism consequent to a deficiency of insulin secretion, insulin action, or both [1]. Hyperglycemia is the major hallmark of both type 1 and type $2 \mathrm{DM}$ and it is the principal etiological factor for the pathogenesis of both macro- and microvascular complications. About $80 \%$ of type $2 \mathrm{DM}$ is

\footnotetext{
* Correspondence: kabirnafisa0@yahoo.com

'Department of Biochemistry, Federal University Dutse, Dutse, Jigawa State, Nigeria

Full list of author information is available at the end of the article
}

reported to be associated with obesity, dyslipidemia and hypertension in addition to insulin resistance [2]. Dyslipidemia of diabetes mellitus has been linked with an increased risk of cardiovascular disease (CVD) development. However, the most common form of dyslipidemia associated with DM is hyperlipidemia; characterized by an elevated plasma triglyceride, cholesterol, small dense LDL, and low HDL cholesterol levels. Previous studies have indicated a strong positive correlation between high plasma lipids; notably of low-density lipoprotein (LDL) and incidence of CVD [3]. Increased lipid peroxidation that can damage cell membranes, lipoproteins and lipid containing 
structures is also linked with an increased CVD risk [4]. Potential mechanisms reported to most likely be responsible for diabetic dyslipidemia include defect in insulin action, hyperglycemia, and peripheral actions of insulin on adipose tissue, changes in liver apoprotein production, defective regulation and action of lipoprotein lipase (LPL), and cholesteryl ester transfer protein (CETP) [5]. In addition, increased adipocyte lipolysis due to poor insulinization results in increased free fatty acid flux from the adipocytes and transport to the liver which eventually causes an increased very low-density lipoprotein (VLDL) and triglyceride secretion in blood [6, 7].

While glycemic control tends to dominate the management of type $1 \mathrm{DM}$, the care for individuals with type 2 DM emphases the treatment of other co-morbid conditions associated with the disease such as life style modification, detection/management of obesity, hypertension, dyslipidemia, and related microvascular and macrovascular complications [7]. Diabetes thus, requires a multiple therapeutic approach to adequately control the multiple metabolic abnormalities and progressive nature of the disease. Recent therapeutic trends in the treatment of DM therefore use combination therapies involving different hypoglycemic drugs and/or insulin [8]. Furthermore, many diabetic patients have opted for alternative plant-based therapies alone or in combination to the conventional hypoglycemic drugs due to their increased cost, non-availability, contraindications, and the assumed safety of medicinal plants. As such, the use of medicinal plants would continue to be popular and common, hence the need to scientifically validate medicinal plants as safer alternatives to the conventional ones. Traditional herbal healers use different plant parts in combination with other plants for the treatment of diabetes with the hope that the combined plants would target different pathologies of the disease, despite that the safety and probable mechanism of action is unknown in addition to the consequences which could be increased morbidity and mortality.

Ethnobotanic surveys have shown that plants such as Leptadenia hastata and Momordica balsamina used most commonly for dietary purposes have gained popularity as ingredients of polyherbal anti-diabetic formulations used by traditional herbal healers in Northern Nigeria [9-11]. Leptadenia hastata (Pers.) Decne, which belongs to the family Asclepiadaceae [12], and Mormodica balsamina Linn, belonging to the family of Cucurbitaceae, are both used for multiple medicinal purposes in Africa [13, 14]. $L$. hastata and M. balsamina have both been reported as important sources of dietary nutrients including fatty acids, beta carotene, protein and minerals, and pharmacologically active phytoconstituents such as phenolic compounds, triterpenoids, and glycosides $[15,16]$. Phytochemical screening of the leaves of $L$. hastata confirmed the presence of major chemical compounds such as alkaloids, flavonoids, tannins, phenolic glycosides, triterpenes, and saponins [13]. The bark and leaves of L. hastata were found to contain mixtures of polyoxypregnane ester derivatives such as ester 12-O-aceylsarcostin, gagaminin, kidjolanin, metaplexigenin, and cynanforidin as well as tritepenes like lupeol, lupeol acetate, and lupeol palmitate $[17,18]$. In a study by Bello et al. [19], the aqueous and methanolic leaf extracts of $L$. hastata reduced the level of blood glucose and blood lipids in both normal and alloxan-induced diabetic rats with a $37.02 \%$ and $69.81 \%$ alpha glucosidase inhibitory effect, respectively. In another study conducted by Gwarzo and Ameen [20], 3-week supplementation of the diet of hyperlipidemia-induced Wistar albino rats with the leaf powder of $L$. hastata was associated with a reduction in serum lipid profile and blood glucose level. Further to this, we conducted a bioassay-guided fractionation and characterization of the methanolic leaf extract of $L$. hastata and our results revealed 5-methyl genistein as one of the major bioactive compounds responsible for its anti-diabetic effect (unpublished).

In the same way, studies of the potential health benefits of the different plant parts of $M$. balsamina have indicated that it possesses activities like anti-microbial, anti-spasmodic, anti-inflammatory, analgesic, anti-HIV, anti-diabetic, antidiarrheal, hepato-protective, anti-malarial, antioxidant, anticancer, and wound-healing properties [14]. These activities could be as a result of the presence of cucurbitane-type triterpenoids from the leaves of $M$. balsamina including balsaminapentaol, balsaminol A and B, cucurbalsaminol A and B [21], and a novel ribosome-inactivating protein (RIP), balsamin from the seeds of the balsam apple [18]. In our newly conducted work, we isolated a pentane type triterpenoid (betulinic acid) from the ethylacetate fraction of the leaves of $M$. balsamina which was found to contribute to its antidiabetic activity (unpublished). Combination of the plant leaves of $L$. hastata and M. balsamina could therefore provide a multi-therapeutic approach for the treatment of diabetes mellitus and its complications. Our previous study had demonstrated the acute and sub-acute anti-hyperglycemic effect of the aqueous leaf extracts of L. hastata and M. balsamina at a dose of 400 and $200 \mathrm{mg} / \mathrm{kg}$ body weight respectively (doses obtained from anti-hyperglycemic screening of the $1 / 5$ th, $1 / 10$ th, and $1 / 20$ th of the $\mathrm{LD}_{50}$ dose; $2000 \mathrm{mg} / \mathrm{kg}$ ) in STZ-induced diabetic [22]. The dose combination was therefore selected and used in the present study to further evaluate its effect on serum lipid profile in STZ-induced diabetic rats.

\section{Methods}

Plant material collection and preparation of aqueous leaf extracts

Fresh leaves of L. hastata and M. balsamina were obtained from natural vegetation in Kumbotso Local 
Government Area of Kano State, Nigeria, in March 2013. Voucher specimens with number L. hastata (900220) and M. balsamina (1139) were deposited at the herbarium of the Department of Biological sciences, Ahmadu Bello University, Zaria, for future reference.

The leaves were rinsed with distilled water to remove dust and undesirable particles, air dried under the shade for 5 days, and grounded into a fine powder using mortar and pestle. The powdered leaves $(500 \mathrm{~g})$ of each plant were extracted with $2 \mathrm{~L}$ of distilled water (1:4; solute: solvent) using cold maceration method at room temperature $\left(25 \pm 2^{\circ} \mathrm{C}\right)$ for $48 \mathrm{~h}$ with constant intermittent shaking. The mixtures were filtered using muslin cloth followed by Whatman No. 1 filter paper and the filtrate was concentrated to dryness in a water bath set at $60{ }^{\circ} \mathrm{C}$. The aqueous extracts were stored at $4{ }^{\circ} \mathrm{C}$ in an air tight container until required.

The aqueous leaf extracts of $L$. hastata $(400 \mathrm{mg})$ and M. balsamina $(200 \mathrm{mg}$ ) per kilogram body weight was combined to obtain the combination dose; LHMB.

\section{Experimental animals and induction of diabetes}

The animals were purchased from the personal farm of Mr. Yakubu Otaro of the Department of Zoology, Bayero University, Kano, and were housed and maintained in the animal house of the same department for this experiment. The animals were allowed to acclimatize for 2 weeks prior to study commencement. They were housed in wire meshed cages under laboratory condition of temperature $25.0 \pm 2{ }^{\circ} \mathrm{C}, 12 \mathrm{~h}$ natural light and dark cycle and were allowed free access to commercial pellet diet (Vital feeds $\odot$, Jos) and tap water ad libitum. The animals received human care in accordance with the requirements of the guide for care and use of laboratory animals [14]. Apparently healthy albino rats (Wistar strain) of both sexes weighing between 240 and $250 \mathrm{~g}$ were injected intraperitoneally with freshly prepared single dose of streptozotocin $(60 \mathrm{mg} / \mathrm{kg}$ ) (Tocoris Bioscience, UK) in $0.1 \mathrm{M}$ cold citrate buffer after overnight starvation as described by Sankar and Pari [23]. Four hours after induction, the diabetic induced rats were maintained on $5 \%$ glucose solution for $24 \mathrm{~h}$ to prevent initial STZ induced hypoglycemia. Diabetes was confirmed in rats after $72 \mathrm{~h}$ post-STZ injection with blood obtained from rat tail vein using a one touch glucometer (Accuchek Roche, Germany) and rats with blood glucose level of $>250 \mathrm{mg} / \mathrm{dl}$ were used for the study.

\section{Experimental design}

A total of 48 rats comprising of diabetic and normal Wistar albino rats were randomly assigned into 8 groups of 6 rats per group as follows:
Group I: served as normal control and were orally administered water only.

Group II: served as diabetic controls and were orally administered water only.

Group III: were normal rats treated orally with $M$. balsamina (MB) (200 mg/kg body weight)

Group IV: were diabetic rats treated orally with $M$. balsamina (MB) (200 mg/kg body weight).

Groups V: were normal rats treated orally with $L$. hastata (LH) (400 mg/kg body weight)

Group VI: were diabetic rats treated orally with $L$. hastata (LH) (400 mg/kg body weight).

Group VII: were normal rats treated orally with LHMB.

Group VIII: were diabetic rats treated orally with LHMB.

After 4 weeks treatment, the experimental animals were sacrificed by cervical decapitation in the fasted state and blood samples were collected from the jugular vein [24]. Blood glucose level was immediately tested with the whole blood collected using a glucometer (Accuchek, Roche Germany) and serum was obtained thereafter from the clotted blood after centrifugation at $3000 \mathrm{rpm}$ for $10 \mathrm{~min}$ for lipid profile estimation.

\section{Biochemical estimations}

Serum total cholesterol and triglyceride levels were determined using commercial kits (Fortress Diagnostic Limited, UK). Serum HDL-C was determined using the polyvalent-anion precipitation method as described by Burstein et al. [25] and Lopes-virella et al. [26] while serum LDL-C and VLDL-C levels were calculated using Fridewald's equation; LDL-C $(\mathrm{mg} / \mathrm{dl})=$ Total Cholesterol - $($ Triglycerides $/ 5$ + HDL-C); VLDL-C (mg/dl) = Triglygeride/5 described by Fridewald et al. [27]. All reagents used in the present study were of analytical grade.

\section{Statistical analysis}

Data obtained was expressed as mean and their standard deviations. Analysis of variance (ANOVA) followed by Tukey's post hoc tests were used to compare experimental groups. Statistical analysis was performed using $\mathrm{R}$ studio software. Values of $\mathrm{P}<0.05$ were considered significant.

\section{Results}

Treatment of STZ-induced diabetic rats with the aqueous leaf extracts of L. hastata, M. balsamina and their combination exerted a 52\%, 61\%, and 64\% decrease in blood glucose respectively at the end of 4 weeks period (Table 1). $M$. balsamina alone and the combination treatments exerted the same anti-hyperglycemic effect as evidenced by the non-significant difference ( $p>0.05$ ) observed in their percentage decrease in blood glucose level. 
Table 1 Percentage decrease in fasting blood glucose (FBG) of normal and STZ-induced diabetic rats treated with aqueous leaf extracts of L. hastata and/or M. balsamina for 4 weeks

\begin{tabular}{|c|c|}
\hline Treatment & Fasting blood glucose (FBG) (mg/dL) \\
\hline Normal control & $95 \pm 1.7^{b}(2)$ \\
\hline Diabetic control & $428 \pm 5.8^{f}(-3)$ \\
\hline $\begin{array}{l}\text { Normal LH } \\
(400 \text { mg/kgbw) }\end{array}$ & $91 \pm 1.0^{\mathrm{b}}(6)$ \\
\hline $\begin{array}{l}\text { Diabetic LH } \\
(400 \mathrm{mg} / \mathrm{kgbw})\end{array}$ & $187 \pm 10.4^{e}(52)$ \\
\hline $\begin{array}{l}\text { Normal MB } \\
(200 \mathrm{mg} / \mathrm{kgbw})\end{array}$ & $88 \pm 3.8^{\mathrm{a}}(8)$ \\
\hline $\begin{array}{l}\text { Diabetic MB } \\
(200 \text { mg/kgbw) }\end{array}$ & $156 \pm 20.9^{d}(61)$ \\
\hline $\begin{array}{l}\text { Normal LHMB } \\
(400+200 \mathrm{mg} / \mathrm{kgbw})\end{array}$ & $82 \pm 3.5^{\mathrm{a}}(11)$ \\
\hline $\begin{array}{l}\text { Diabetic LHMB } \\
(400+200 \mathrm{mg} / \mathrm{kgbw})\end{array}$ & $145 \pm 15.0^{c}(64)$ \\
\hline
\end{tabular}

As shown in Fig. 1, the persistent hyperglycemia observed in the untreated diabetic rats was accompanied with significantly elevated $(\mathrm{p}<0.05)$ levels of blood total cholesterol, triglyceride and VLDL-C and significantly decreased ( $p<0.05$ ) level of HDL-C when compared to the normal controls. However, the high blood lipids observed in the diabetic rats was ameliorated by the treatment with L. hastata, M. balsamina, and their combination with significantly decreased $(\mathrm{p}<0.05)$ levels of total cholesterol, triglyceride and VLDL-C and increased ( $p>0.05$ ) level of HDL-C when compared to the untreated diabetic rats. Additionally, significantly higher levels of total cholesterol, triglyceride, VLDL-C, and LDL-C were observed in the diabetic rats treated singly with the extracts when compared to the combination-treated diabetic rats. This indicates potent lipid-lowering effect of the polyherbal combination on the diabetic rats. In contrast, no significant $(\mathrm{p}>0.05$ ) change in HDL-C level was observed between diabetic rats treated with single and combination treatments (Fig. 1).

With respect to the normoglycemic rats, a significantly lower $(\mathrm{p}<0.05)$ levels of total cholesterol, triglyceride, and LDL-C, and insignificantly higher ( $\mathrm{p}>0.05)$ HDL-C level was observed in the rats treated singly with $L$. hastata and M. balsamina as compared to the normal control and combination treated group (Fig. 1).

STZ Streptozotocin, LH Leptadenia hastata, MB Momordica balsamina, LHMB combination of $L$. hastata and M. balsamina. Values expressed are means with their standard deviations for six animals each per group. Values with different a-f superscripts within the same column are statistically significant (Tukey's post hoc test, $\mathrm{P}<0.05)$. Figures in parentheses show percentage decrease over experimental period

\section{Discussion}

Severity of hyperlipidemia observed in diabetes appears to depend on the extent of insulin deficiency and interaction of lipids with free radicals which play important roles in tissue damage and consequently diabetic complications [28]. With the progression of diabetes mellitus in patients, treatment is usually modified to contain two or more hypoglycemic agents, despite their major drawbacks of having side effects when used alone and in combination, necessitating the search for safer alternatives. Plants contain a large compound-base that can provide hypoglycemic substitutes that can be safely combined and without drastic side effects, hence the need for scientific validation of traditionally used plants.

Plant extracts or their isolated phytochemicals have been used for decades to ameliorate high blood glucose level. In consistent to the present study, several other studies have confirmed the ability of streptozotocin using a single dose of $60 \mathrm{mg} / \mathrm{kg}$ to induce hyperglycemia [29] via the selective necrosis of the pancreatic beta cells which results in diminished insulin secretion and suppressed hormone sensitive lipoprotein lipase of triacylglycerol activity [30]. Hyperglycemia induced using streptozotocin is reported to be accompanied by hypoinsulinemia, dyslipidemia, kidney damage, cataract formation, and weight loss $[31,32]$. These pathologies are usually accompanied with a markedly elevated glycated hemoglobin level for up to 23 weeks post-induction of diabetes [33]. In this perspective, researchers worldwide have used streptozotocin-induced model of diabetes as an inexpensive, simple, and available method to study diabetes. Steptozotocin-induced type 1 diabetes models are well-accepted in practice as animal models that recapitulate the different types of human diabetes and can therefore be used for the elucidation of diabetic pathogenesis and screening of potential glucose-lowering agents [34]. Furthermore, hyperglycemia of streptozotocin is reported to be stable for up to 24 weeks without intervention [35].

The hypoglycemic and lipid-lowering effect of $L$. hastata and M. balsamina observed in the present study is consistent to studies by Karumi and Bobboi [36], Karumi et al. [14], Bello et al. [19], Ayoub et al. [37], and Gwarzo and Ameen [20]. Treatment with M. balsamina alone depicted the same anti-diabetic efficacy as the combination treatment; this could have been due to the length of the study period. The anti-hyperglycemic efficacy could have been higher in the combination group if the study period was extended. However, the results validate the traditional use of the anti-diabetic polyherbal combination. As observed in the present study, glycemic control appears to be paramount for the control of high blood lipid level; as blood lipid levels were ameliorated with lower blood glucose level. 

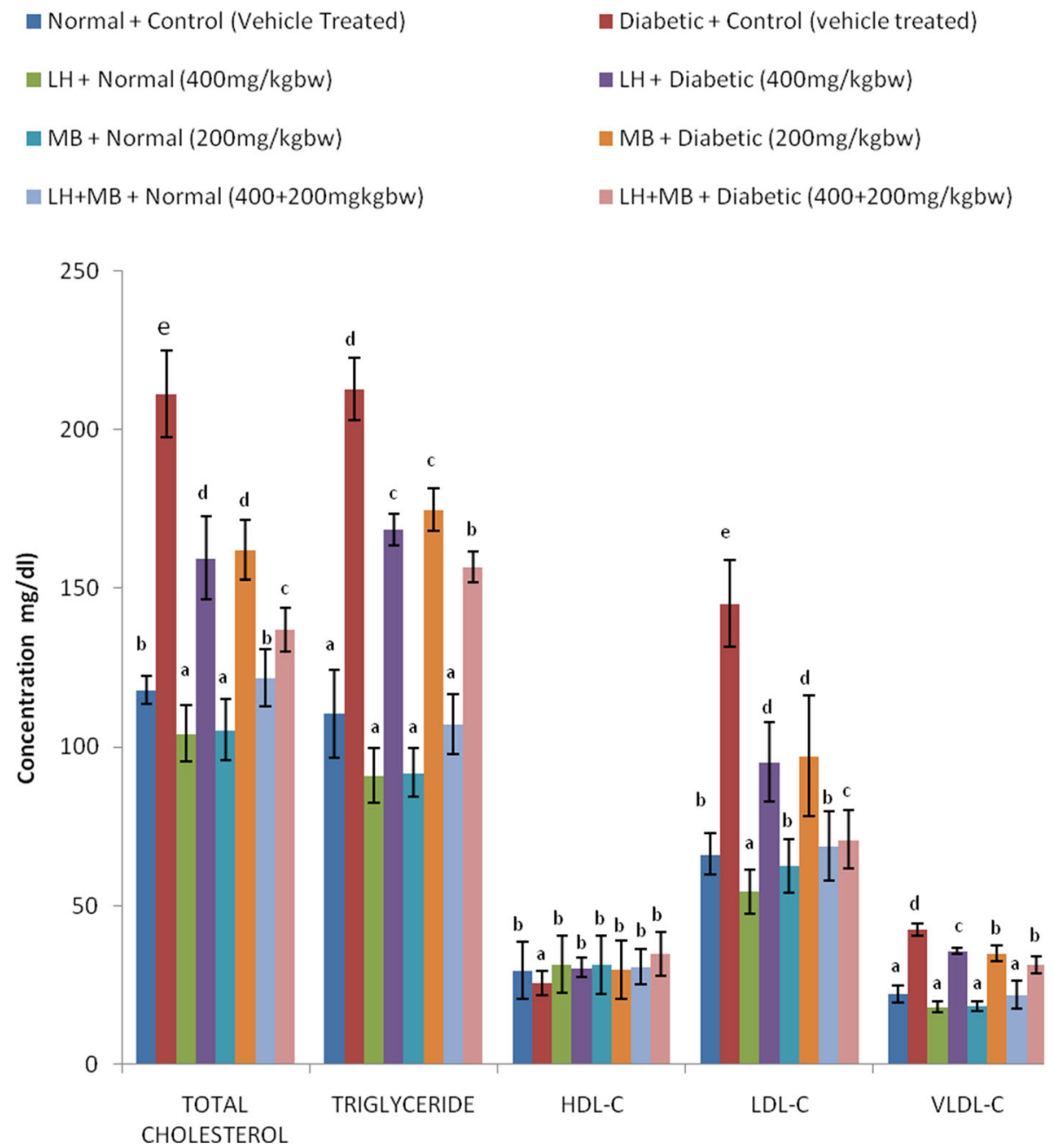

Fig. 1 Effect of aqueous leaf extracts of L. hastata, M. balsamina and their combination on lipid profile of normal and STZ-induced diabetic rats. Values expressed are means with their Standard Deviations represented as error bars for six animals per group. Different superscripts a-d for each parameter indicate statistical significance at value of $\mathrm{P}<0.05$ (Tukey's post hoc test)

Insulin has an important role in the regulation of lipid metabolism most especially its effect on the activity of hormone sensitive lipoprotein lipase. Low insulin level that accompany hyperglycemia has been reported to significantly promote the conversion of free fatty acids into phospholipids and cholesterol which are released into the blood resulting in high blood cholesterol levels of diabetic patients $[6,7]$. This is consequent to the activation of lipoprotein lipase and inhibition of lecithin cholesterol acyl- transferase which causes an elevated blood VLDL, LDL, and triglyceride levels with a concomitant decrease in HDL [38]. In agreement with our results, increased serum triacylglycerol and cholesterol concentration due to their increased production by the liver and increased VLDL-C and LDL have been reported in many studies [7, 38]. Furthermore, long-term hyperglycemia of diabetes mellitus causes small dense LDL particles to be more atherogenic because they are easily glycated and susceptible to oxidation as such increases the risk of developing cardiovascular diseases in diabetic patients [3, 6]. Glycation of lipoproteins and apolipoproteins have been shown to play significant role in the development of arthrosclerosis [39]. The hypolipidemic activity of the polyherbal combination containing $L$. hastata and $M$. balsamina could therefore be an indication of its antiatherogenic potential and consequently potential for lowering the risk of CVD.

Low HDL cholesterol level is also implicated as an underlying risk of CVD development. This finding is consistent with our results and could be due to an increased non-enzymatic glycation of HDL-C resulting in its increased clearance [40]. While our study did not observe a significant improvement of HDL level after treatment with the plant extracts alone and in combination, the finding is however in agreement with the study of Ighodaro et al. [41]. This emphasizes the need for long- 
term research in order to ascertain the lipid-lowering mechanism of action of the medicinal plants as potential drug candidates.

Phytochemical compounds reported to be found in $L$. hastata and $M$. balsamina $[13,21]$ may be responsible for their anti-diabetic activities. The blood lipids-lowering effect exerted by the aqueous leaf extracts might have worked synergistically or additively in the polyherbal combination. Emerging research on mechanism of action of phytochemical compounds with hypolipidemic and antihyperglycemic potentials are reported to be through the inhibition of cholesterol synthesis, lipoprotein lipase, HMG-CoA reductase, or reduction in the NADPH required for fatty acids synthesis [7]. Plants rich in flavonoids, alkaloids, and tannins are reported to have significant blood lipid-lowering effects [42]. Cucurbitane type triterpenoids [15] and pentancyclic type tritepenoids; betulinic acid (unpublished) reported in M. balsamina and lupeol palmitate [16] and isoflavone; 5-methyl genistein (unpublished) in L. hastata could therefore be responsible for their blood lipid- and glucose-lowering effects. The anti-diabetic, antioxidant, inhibitory intestinal glucose and lipid absorption, and insulinomematic activities of the compounds in L. hastata and M. balsamina $[16,19,43,44]$ have been reported. Recent studies have demonstrated the ability of betulinic acid found in M. balsamina to effectively ameliorate hyperglycemia as well as to exert hypolipidemic, antioxidant, anti-AGE, and antiobesity activities [45]. Genistein on the other hand found in $L$. hastata has been shown to be a strong antioxidant capable of removing damaging free radicals and reduce lipid peroxidation through increases in activity of antioxidant enzymes including glutathione peroxidase, superoxide dismutase, and glutathione reductase [30].

Maceration extraction procedure used in the present study, which uses low temperature and produces a product without the degradation of the heat labile compounds found in the plant leaves, could have preserved the potency of the lipid-lowering phytochemicals [46]. The use of aqueous extract in the present study is in consonance to how these plant extracts are used by the traditional herbal healers. However, further studies using non polar solvent extracts of $L$. hastata and M. balsamina could provide more potent hypolipidemic agents to exert an enhanced anti-diabetic and anti-hyperlipidemic effect of the polyherbal combination. An aspect for future study is to unravel the mechanism of anti-diabetic action of $L$. hastata and M. balsamina and to produce a polyherbal supplement for diabetics.

\section{Conclusion}

Our findings demonstrated the potential anti-hyperglycemic and blood lipid-lowering effects (hypolipidemia) of L. hastata and M. balsamina alone and in combination. The hypolipidemic activity could be consequent to an improved glycemia as such could be beneficial for managing diabetes mellitus and its associated complications. Thus, this research validates the traditional usage and efficacy of the polyherbal combination in exerting both anti-hyperglycemic and lipid lowering effects.

\section{Abbreviations \\ HDL: High-density lipoprotein cholesterol; VLDL: Very low-density lipoprotein; LDL: Low-density lipoprotein; FBG: Fasting blood glucose; \\ STZ: Streptozotocin; DM: Diabetes mellitus; CVD: Cardiovascular disease}

\section{Acknowledgements}

The authors express sincere appreciation to Mr. Yakubu Otaro of the Department of Zoology, Bayero University Kano, for providing animal care and handling.

\section{Plant authentication}

The plant leaves used for this study were authenticated by Musa Muhammad of the herbarium, Department of Biological Sciences, Ahmadu Bello University, Zaria.

\section{Authors' contributions}

NK, UIA, DBJ, and HMI conceived and designed the study. NK, UIA, DBJ, HMI, and MKA were responsible for acquisition of data, analysis and interpretation of data obtained, and drafting of manuscript. UIA, DBJ, HMI, and MKA supervised the work and NK, UIA, and MKA revised and corrected the manuscript. All authors read and approved the final manuscript.

\section{Funding}

The authors have no funding to report.

\section{Availability of data and materials}

The data used to generate the findings of this study are available from the corresponding author upon request.

\section{Declarations}

Ethics approval and consent to participate

The study protocol was approved by the Faculty of Life Sciences scientific and biochemical ethics committee, Ahmadu Bello University, Zaria, under registration number Ph.D/Scie/3691/2011-2012.

\section{Consent for publication \\ Not applicable.}

\section{Competing interests}

The authors declare that they have no competing interests.

\section{Author details}

'Department of Biochemistry, Federal University Dutse, Dutse, Jigawa State, Nigeria. ${ }^{2}$ Department of Biochemistry, Ahmadu Bello University, Zaria, Kaduna State, Nigeria. ${ }^{3}$ Department of Biochemistry, Bayero University Kano, State, Kano, Nigeria.

Received: 13 November 2019 Accepted: 18 May 2021

Published online: 27 May 2021

References

1. International Diabetes Federation (IDF) (2013) Diabetes Atlas, 5th edn. International Diabetes Federation, Brussels, Belgium http://www.idf.org/ diabetesatlas/downloaded in 30/11/2013

2. King MW (2014) Diabetes mellitus. The medical biochemistry page http:// themedicalbiochemistrypage.org/diabetes.php

3. Mannine V, Tenkanene L, Koskin P (1992) Joint effect of serum triglyceride and $\mathrm{LDL}$ cholesterol and $\mathrm{HDL}$ cholesterol concentration on chronary heart disease-risk in the Hwlsinki heart study: implication for treatment. Circulation 85:34-45 
4. Parikh NH, Parikh PK, Kothari C (2014) Indigenous plant medicines for healthcare: treatment of diabetes mellitus and hyperlipidemia. Chin J Nat Med 12(5):335-344. https://doi.org/10.1016/S1875-5364(14)60041-8

5. Goldberg IR (2001) Diabetic dyslipidemia: causes and consequences. J Clin Endoctinol Metab 86(3):965-971

6. Verges B (2009) Lipid modification in type 2 diabetes: the role of $L D L$ and HDL. Fundam Clin Pharmacol 23(6):681-685. https://doi.org/10.1111/j.14728206.2009.00739.x

7. Nikiema JB, Vanhaelen-Fastre R, Vanhaelen M, Fontaine J, Grace CDE, Heenen M (2001) Effects of anti-inflammatory triterpenes isolated from Leptadenia hastata latex on keratinocyte proliferation. Phytother Res 15(2): 131-134. https://doi.org/10.1002/ptr.700

8. Blonde L, Rosenstrock J, Mooradian AD, Piper BA, Henry D (2002) Glyburide/ metformin combination product is safe and efficacious in patients with type 2 diabetes failing sulphonylurea therapy. Diabetes Obes Metab 4(6):368-375. https://doi.org/10.1046/j.1463-1326.2002.00229.x

9. Aliero BL, Umar MA, Suberu HA, Abubakar A (2001) A hand book of common plants in Northern Western Nigeria, p 78

10. Aliero AA, Wara SH (2009) Validating the medicinal potential of Leptadenia hastata. Afr J Pharm Pharmacol 3(6):335-338

11. Togola A, Austarcheim I, Theis A, Diallo D, Paulsen BS (2008) Ethanopharmacolgical uses of Ethria senegalensis: A comparison of three areas in Mali, and a link between traditional knowledge and modern biological science. J Ethanobiol Ethanomed 4(1):6. https://doi.org/10.1186/ 746-4269-4-6

12. Burkil HM (1985) Entry for Leptadenia hastata (Family Asclepiadaceae). In: The useful plants of West Africa. Vol 1. Royal Botanic Gardens Kero UK, pp 597-599

13. Thomas SD (2012) Lepatadenia hastata: a review of its traditional uses and its pharmacological activity. Med Chem 2:148-150. https://doi.org/10.41 72/2161-9444.1000132

14. Karumi Y, Onyeyili P, Ogugbuaja OV (2003) Antinflammatory and antiinociptive (Analgesic) properties of Momordica balsamina Lin (balsam apple) leaves in rats. Pak J Biol Sci 6(17):1515-1518. https://doi.org/10.3923/ pjbs.2003.1515.1518

15. Hassan LG, Umar KJ (2006) Nutritional value of balsam apple (Momordica balsamina) leaves. Pak J Nutr 5(6):522-529. https://doi.org/10.3923/pjn.2006. 522.529

16. Thakur GS, Bag M, Sanodiya BS, Bhadouriya P, Debnath M, Prasad GB, Bisen PS (2009) Mormodica balsamina: A medicinal and neutraceutical plant for healthcare management. Curr Pharma Biotech 10(7):667-682. https://doi. org/10.2174/138920109789542066

17. Aquino R, Peluso G, Tommassi N, Simone F, Pizza C (1996) New polyoxypregnane ester derivates from Leptadenia hastata. J Nat Prod 59(6): 555-564. https://doi.org/10.1021/np960251e

18. Kaur I, Yadav SK, Hariprasad G, Gupta RC, Srinivasan A, Btara JK, Puri M (2011) Balsamin: A novel ribosome-inactivating protein from the seed of balsam apple (Momordica balsamina). J Amino Acids 43(2):973-981

19. Bello A, Aliero AA, Saidu Y, Muhammad S (2011) Hypoglycaemic and hypolipidemic effects of Leptadenia hastata (pers) decne in alloxan-induced diabetic rats. Nig J Basic Appl Sci 19:187-192

20. Gwarzo MY, Ameen ZS (2015) Assessment of hypolipidemic effect of Leptadenia hastata leaves in albino rats. Adv J Food Sci Technol 7(1):1-5. https://doi.org/10.19026/ajfst.7.1253

21. Ramalhete C, Mansoor TA, Mulhoro S et al (2009) Cucurbitane-type triterpenoids from the African plant Momordica balsamina. J Nat Prod 72(11):2009-2013. https://doi.org/10.1021/np900457u

22. Kabir N, Umar Al, James DB, Inuwa HM, Atiku MK (2019) Antidiabetic potentials of aqueous leaf extracts of Momordica balsamina Linn and Leptadenia hastata (pers) decne alone and in combination in streptozotocin-induced diabetic rats. Trop J Nat Prod Res 3(1):10-16. https:// doi.org/10.26538/tjnpr/v3il.3

23. Sankar N, Pari N (2011) Influence of thymoquinone on glycoprotein changes in experimental hyperglycemic rats. Neurol Dis Ther 1:51-55

24. Clark JD, Gebhart GF, Gonder JC, Keeling ME, Kohn DF (1997) The 1996 guide for the care and use of laboratory animals. ILAR 38(1):41-48 http://aca demic.oup.com/ilarjournal/article-abstract/38/1/41/664018. retrieved online on 2 November, 2019

25. Brustein M, Scholnick HR, Morfin R (1970) Rapid method for isolation of lipoproteins from human serum by precipitation with polyanions. J Lipid Res 11(6):583-595. https://doi.org/10.1016/S0022-2275(20)42943-8
26. Lopes-Virella MF, Stone P, Ellis S, Colwell JA (1977) Cholesterol determination in high density methods. Clin Chem 23(5):882-884. https:// doi.org/10.1093/clinchem/23.5.882

27. Fridewald WT, Levey RT, Fredrickson DS (1972) Estimation of the concentration of low density cholesterol in plasma without use of preparative ultracentrifuge. Clin Chem 18(6):499-502. https://doi.org/10.1 093/clinchem/18.6.499

28. Grant RW, Cagliero E, Murphy-Sheehy P, Singer DE, Nathan DM, Meigs JB (2002) Comparison of hyperglycemia, hypertension and hypercholesterolemia management in patients with type 2 diabetes. Am J med 112:603-609

29. Weis M (1982) Streptozotocin: a review of its pharmacology, efficacy and toxicity. Cancer Treat Rev 66:427

30. Mazumder AR, Hongsprabhas P (2016) Genistein as antioxidant and antibrowning agents in in vivo and in vitro: A review. Biomed Pharmacother 82:379-392. https://doi.org/10.1016/j.biopha.2016.05.023

31. Forbes JM, Cooper ME (2013) Mechanisms of diabetic complications. Physiol Rev 93(1):137-188. https://doi.org/10.1152/physrev.00045.2011

32. Chahil TJ, Ginsberg HN (2006) Diabetic dyslipidemia. Endocrinol Metab Clin 35(3):491-510

33. Wang-Fischer $Y$, Garyantes $T$ (2018) Improving the reliability and utility of streptozotocin-induced rat diabetic model. J Diabetes Res 8054073:14. https://doi.org/10.1155/2018/8054073

34. Wu J, Yan L (2015) Streptozotocin-induced type 1 diabetes in rodents as a model for studying mitochondrial mechanisms of diabetic $\beta$ cell glucotoxicity. Diabet Metab Synd Ob 8:181-188. https://doi.org/10.2147/ DMSO.S82272

35. Wei M, Smith MT et al (2003) The streptozotocin-diabetic rat as a model of the chronic complications of human diabetes. Heart Lung Circ 12(1):44-50. https://doi.org/10.1046/j.1444-2892.2003.00160.x

36. Karumi Y, Bobboi A (1999) Hypoglycemic effects of balsam apple (Momordica balsamina) in Alloxan Diabetic Male Rabbits. Biochem 9:795-808

37. Ayoub SM, Rao S, Byregowada SM, Satyanarayana L, Bhat N, Shridhar NB, Shridhar BR (2013) Evaluation of hypoglycemic effect of Momordica charantia extract in distilled water in streptozotocin-diabetic rats. Bra J Vet Pathol 6(2):56-64

38. Shirwaikar A, Rajendran K, Kumar CD, Bodla R (2004) Antidiabetic activity of aqueous leaf extract of Annona squamosa in streptozotocin-nicotinamide type 2 diabetic rats. J ethanopharmacol 91(1):171-175. https://doi.org/10.1 016/j.jep.2003.12.017

39. Ferretti G, Rabini RA, Bacchetti T, Vignini A, Salvolini E, Ravaglia E, Curatola G, Mazzanti L (2002) Glycated low density lipoproteins modify platelet properties: a compositional and functional study. Clin Endocrinol Metab 87: 2180-2184

40. Andallu B, Vinay Kumar AV, Varadacharyulu NC (2009) Lipid abnormalities in Streptozotocin-diabetes: Amelioration by Morus indica L. Suguna leaves. Int J Diabetes Dev Ctries 29(3):123-128. https:/doi.org/10.4103/0973-3930.54289

41. Ighodaro OM, Akinloye OA, Ugbaja RN, Omotainse SO (2017) Sapium ellipticum (Hochst.) Paxethanol leaf extract maintains lipid homeostasis in streptozotocin-induced diabetic rats. Int Scholarly Res Not 6463139:5. https://doi.org/10.1155/2017/6463139

42. Akindahunsi AA, Salawu SO (2005) Phytochemical screening and nutrientantinutrient composition of selected tropical green leafy vegetables. Afr J Biotechnol 4:563-568

43. Tayyab SS (2013) Antidiabetic, hypolipidemic and antioxidant activity of Momordica charantia on type-II diabetic patient in Allahabad, India. Int $J$ Pharm Bio Sci 4:932-940

44. Bayala B, Telefo PB, Bassole IHN, Tamboura HH, Belemfough RG et al (2011) Anti-spermatogenic activity of Leptadenia hastata (Pers) decne leaf stems aqueous extracts in male wistar rats. J Pharmacol Toxicol 6:1-9

45. Nazaruk J, Kluczyk MB (2015) The role of triterpenes in the management of diabetes mellitus and its complications. Phytochem Rev 14(4):675-690. https://doi.org/10.1007/s11101-014-9369-X

46. Wu C, Wang F, Liu J, Zou Y, Chen X (2015) A comparison of volatile fractions obtained from Lonicera macranthoides via different extraction processes: ultrasound, microwave, soxhlet extraction, hydrodistillation and cold maceration. Integr Med Res 4:171-177

\section{Publisher's Note}

Springer Nature remains neutral with regard to jurisdictional claims in published maps and institutional affiliations. 